\title{
INTERNATIONAL CONFIDENCE IN ITALIAN ECONOMY. A SPREAD AND GAMBLING ANALYSIS
}

\author{
Aurora MURGEA 1
}

DOI: 10.1515/tjeb-2015-0005

\begin{abstract}
Gambling is an ancient human activity with a prevalent position nowadays both as a social entertainment activity and as a way to gain money effortless. Every country has its specific pattern in gambling determined both by its cultural and macroeconomic determinants and by its national regulatory framework. Macroeconomic variables as gross national income per capita, annual variation of GDP or unemployment were previously proved to be connected with the gambling industry. The aim of this paper is to analyze the effects generated by the internal and external loss of confidence in the Italian economy, as an effect of the latest financial crisis, over the Italian gambling industry. The level of spread between the 10 years yield of Italian and German government bonds is used as a proxy for the international trust in the Italian economy and the Economic Sentiment Indicator is used to describe the Italian citizens' confidence. The main results show a strong positive, statistically significant correlation between skill games and spread and an unexpected negative significant correlations between spread and lottery, one of the purely fortune games that was often seen as an ultimate chance to survive the crisis. The Economic Sentiment Indicator seems not to be correlated with any of the gambling categories.
\end{abstract}

Keywords: behaviour, gambling, crisis, spread.

JEL Classification: D10, D70, D81, D84, G01.

${ }^{1}$ Associate professor PhD, West University of Timisoara, Romania 
Murgea, A. (2015).

\section{Introduction}

In the last years there has been a growing body of literature dedicated to the psychology of gambling, to the social and cultural motivations and factors of influence and not in the last place to the pathological gambling, its diagnosis and treatment. Despite the fact that many countries choose to turn to legalized gambling (casinos and other forms) to alleviate fiscal stress caused by the financial crises, the gambling research in the economics field is relatively scarce.

Apparently very simple, the connection between the economic turmoil and gambling industry turns out to be much more complex at a closer look since the evolution of gambling propensity during crisis can be either positive or negative.

During the crises, due to a reduced amount of income, the level of resources committed for entertainment and the gambling propensity has serious reasons to decrease. A short look at the gambling industry data proves that there are countries and market segments where the effect of reduced resources for gambling is visible. For instance, in France the revenues of brick-and-mortar casinos have decreased with $2 \%$ in 2010 compared to 2009, the UK casinos revenues have fallen with 3\% and the gross gaming revenues in USA have shown an increase slowdown in the same period (Ernst\&Young, 2011). Several scholars' researches also support this idea ${ }^{1}$.

On the other side there are a lot of changes generated by the crises that could enhance the gambling propensity.

The recent crisis has demonstrated that sometimes the economies are not easy to understand, the markets are not efficient and that hard work or honest efforts are not enough to get and maintain the individuals' financial stability. As a result, the individual behaviour could shift. Since the effort was not rewarded the individuals will be tempted to rely on luck and to incorporate in their activities less rational and more playful attempts to improve financial status, such as gambling (Downes, Davies, David \& Stone, 2006). Plus, considering the important financial difficulties that often arise some individuals could become convinced that only a miracle could represent the escape from this situation.

\footnotetext{
${ }^{1} \mathrm{Gu}(1999)$ investigates the impact of the Asian crises on Las Vegas casino drops of two games played especially by Asians, baccarat and pai gow, and concluded that the decreases in the most popular game from those two, baccarat, are much more important in volume than the expected ones. The same decline in baccarat wins in Las Vegas casino during the crises is analyzed by Raab and Schwer (2003) but the crisis effect seems to die really fast. A newer study (Horwath \& Paap, 2012) analyzes three main types of gambling activities: casino gambling, lottery and pari-mutuel wagering based on a 51 years evolutions and conclude that just lottery seems to be insensitive to the financial crises. Casino expenditures growth decreases and pari-mutuel wagering declines during recession.
}

\section{DE GRUYTER OPEN}


Murgea, A. (2015).

International Confidence in Italian Economy. A Spread and Gambling Analysis

Gambling is the easiest action leading to a possible miracle they can expect- one dollar could give the chance to win a jackpot. This is why in difficult financial situations people may be more attracted by the tiny but real chance of winning then in more calm periods (Mikesell, 1994). Going deeper, financial crises have an important impact on two important gambling motivations ${ }^{2}$ : anxiety and boredom. During the economic downturn people have to constantly face the fear that they could loose their jobs or they would have to bare wages' cuts. The anxiety and emotional stress arising from this may contribute to gambling problems (Lightsey \& Husley, 2002). In the same time the unemployment ${ }^{3}$ determine an increased spare time and boredom that constitute an often present motivation in the interviews gamblers (Weatherly, Montes \& Christopher, 2010).

The post-crisis public policy oriented towards economic growth could also represent a triggering fact for the gambling propensity. Confronted with decreased incomes during the economic downturn the states often take into consideration expanding the gambling industry, legalizing different segments or allowing aggressive gambling advertising to balance the budget and reduce unemployment (Dadayan \& Ward, 2009; Richard, 2010).

According to our knowledge there is no study that empirically investigates the relationship between financial crises and the gambling industry in Italy ${ }^{4}$. The previous studies conducted on Asian crises or the ones regarding the last USA crises are set in a different time or cultural scenario that does not fit Italy. Certain cultural groups are more vulnerable than others to begin gambling and to develop gambling problems (Raylu and Oei, 2004) because gambling as any social behaviour becomes consistent by reference to the context where occurs (Abt \& McGurrin, 1992). Different cultures have particular attitudes and their own ethics towards gambling from total abstinence in some Moslem groups, to a permissive approach in American and European societies or high propensity for gambling among Chinese and other Asian cultures. In each country gambling has different roots and cultural patterns, transmitted from generation to generation. That makes very hard to apply the founding or patterns from one country to another.

Italy has some of the oldest roots in gambling in Europe. The ancient Romans had seen the public games as an opportunity to win easy money betting on the winners and to escape

\footnotetext{
${ }^{2} \mathrm{~A}$ more extended presentations of the gabling motivations is realized in the second paragraph

${ }^{3}$ The correlation between unemployment and gambling activities, especially lottery is also analyzed in financial studies. Mikesell (1994) and Kumar (2009) point out that the increase in unemployment rate is positively correlated with the amount of money used to play in lotteries games.

${ }^{4}$ A very pertinent analysis of the gambling patterns in Italy is realized by Bastiani et al. (2011). Their study is using different socio-demografic variables as gender, age, level of education, geographical residence to depict some gambling patterns among categories and ddiscuses also the crisis influence on Italian gambling industry but due to a different objectives, does not include an empirical analysis to investigate this relationship
}

\section{DE GRUYTER OPEN}


Murgea, A. (2015).

International Confidence in Italian Economy. A Spread and Gambling Analysis

boredom (Frasca, 2008). The ludus culture was deeply rooted in the ancient Italian culture back then as a way to control the people. For instance, in Augusto's period 66 days per year were dedicated to public games. In Marco Aurelio's period the number has increased to 135 days per year. A great development of gambling is associated with Venetian nobles. The most quoted examples around 1500-1700, are playing cards (especially bassetta ${ }^{5}$ ) and wagering on the outcome of elections. Italy has also the first legal gambling houses in Europe, called Ridotto ${ }^{6}$, created in Venice in 1638 by the city leaders in the context of growing popularity of mercantile gambling (Pavan, 1993).

Nowadays, Italy occupies the first position in Europe as gambling industry with a 87 billions euro total amount waged in the end of 2012 (Calvosa, 2013)7. More than that Italy is one of the fastest-growing gaming market in EU, and one of the few countries in world where the gambling industry seems to be stimulated by the crises. For instance the largest segment of the market, slot machines, had a 19\% increase in 2010 compared to 2009, contrary with the global general decreases caused by the crisis (Ernst\&Young, 2011). This growth was encouraged by changing the perception about gambling. After the earthquake L'Aquila, to be able to cover the damages, the Government has started a gaming reform process (Abruzzo Decree from April 28, 20098), has launched a massive public campaign encouraging people to gamble in order to help people in the earthquake and fostered the idea that the development of this industry could reduce unemployment and generate economic development. The gaming was presented as a harmless and respectable pastime despite the potential ruining of the Italian families lives.

The present paper completes with Italy's case the literature regarding the impact of the financial crises on the gambling industry. The latest financial crisis caused both a lost of confidence in international financial markets and a lost of confidence among the Italian

\footnotetext{
${ }^{5}$ Bassetta is an old Italian card play where players bet on the possibility that particular cards will be turned up by the dealer

6 "Ridotto" comes from the Italian word "riddure", that means to "close off" or "make private"

${ }^{7}$ Italy has the eight largest economies in the world and the third largest in Eurozone. Starting from more than $4 \%$ growth in GDP in the first years after joining the European Union, in the last years and especially during and after the crises, the government has been trying to revive the economy increasing public spending due to the GDP decrease (from a record $-3,5 \%$ in the first quarter of 2009 to $-0.4 \%$ in the last quarter of 2012 and $-0,1 \%$ in the end of 2014). As a result the public debt and public deficit reached an unsustainable level and the country is facing tough austerity measures. This economic situation made Italy chose alternative measures to cover the deficit as encouraging gambling industry in order to increase the budgetary incomes without imposing some further taxes on production segments.

${ }^{8}$ The Abruzzo Decree legalized online fixed odds games of chance, online poker and ring games and introduced a profit-based tax regime with a flat $20 \%$ rate applying to the games listed above instead of the penalized turnoverbased regime which continues to be applied just from sports and horse races betting, bingo, lotteries and skill game.
}

\section{DE GRUYTER OPEN}


Murgea, A. (2015).

International Confidence in Italian Economy. A Spread and Gambling Analysis

citizens. Our main goal is to analyse the correlation between those two psychological effects and the evolution of eight gambling industry sectors. The level of spread between the 10 years yield of Italian and German government bonds is chosen as a referential for the international financial market confidence in Italian economy post-crisis and the Economic Sentiment Indicator is used to describe the Italian citizens' confidence. The main assumption we make is that, at least for certain market segments one of these effects or both of them are correlated with the gambling evolutions.

The outline of the remainder of this paper is as follows. In Section 2 the gambling motivations are presented as a basis for the future empirical analysis. Section 3 includes the data set, Section 4 is dedicated to methodology and discussions and Section 5 concludes.

\section{Gambling Motivations: Ancient to Present Times}

Gambling is an ancient human activity present in many cultures ${ }^{9}$. A large body of literature is dedicated to the factors and motivations that drive the desire to gamble, sometimes beyond the line of a simple recreational activity.

Ancient people believed that the forces of good control random events and saw gambling as a way to connect with Gods, to find out his will and to predict the future. For instance in the Greek mythology, Zeus and Aphrodite could be contacted by dice toss. The practice of "casting lots" is present in numerous cases in the Old Testament and in the New Testament as a way to determine several offices and functions in the temple or to take important decisions ${ }^{10}$. Initially gambling was not used as an entertainment activity, being considered dangerous for the gamblers (Gabriel, 2003).

During time, the motivations have started to change. Gambling became an alternative social entertainment and a way to get money effortless (Ladouceur \& Walker, 1998). Some motivations present in the literature also connects with fun, enjoyment and thrill of the action (Klingemann, 1995), with desire to escape boredom or unhappy job/home (Jacobs, 1986; McCormick, 1987; Weatherly et al., 2010) or cope with depression or anxiety (Jacobs, 1986; Blaszczynski \& Nower, 2002).

In the last decades, different scholars have analyzed the gambling motivation and have proposed scales to measure it. For instance Chantal et.al. (1994) include in the Gambling Motivation Scale, as main motivational factors, three types of internal and external forces:

\footnotetext{
${ }^{9}$ For a detailed map of gambling dispersion through history see Binde (2005)

${ }^{10}$ For instance tossing the dice is used in Isaiah $(34: 17)$ to determine the ownership of land.
} 
Murgea, A. (2015).

International Confidence in Italian Economy. A Spread and Gambling Analysis

intrinsic motivation, extrinsic motivation and amotivation. Intrinsic motivations contain the desire to understand and learn something new, to acquire new skills or simple to raise the arousal level. The extrinsic motivations are connected with rewards (usually monetary), mood change (through anxiety reduction or tension or guilt release) and attain a certain internal value as the others respect. Amotivation occurs usually when the gambler has lost the sense of control and choice and the gambling behaviour is more justified by his incapacity to stop then by a rational intrinsic or extrinsic motivation.

The prevalence of certain motivation seems to be different among the two genders. Coman et al. (1997) conducted a study on the principal gambling motivations using the answers in a G-line (a telephone confidential service used for problem gamblers). Their results shown that the main motivations in males are: financial reasons, excitement, pleasure and stress reduction (in this order). For women the hierarchy seems to be a bit different but the motivations look pretty alike: boredom, loneliness, stress reduction, pleasure and financial reasons.

As motivations specific to the non-pathological gamblers, Neighbors et al. (2002) had identified a comprehensive set of 16 gambling motivation among 184 undergraduate college student gamblers11: money perspectives, enjoyment/fun, excitement, social interaction, boredom alleviation, winning experience, competition, conformity with the rest of the fiends, risk seeking, skill development, interestingness, coping with problems, experience of challenge, drinking, test one's luck, chasing trying to get back the lost money. Testing just the most important reasons for gambling in the first 5 places the participants had point out: money $(42,7 \%)$, enjoyment $(23 \%)$, social reasons $(11,2 \%)$, excitement $(7,3 \%)$ and boredom $(2,8 \%)$.

In a study regarding the pathological gambling, Lee et.al.(2007) proposed a five-factor gambling motivation model that encomprises: monetary reasons, social motives, amusement, excitement and avoidance. Testing two alternative models, one parallel model in which each motivational factor act independently one from the other and a second model in which the monetary factor mediate the other factors influence, the authors conclude that in fact the monetary model is much more effective in explaining the influence of gambling motives on gambling severity. The importance of money as a motivational and reinforcing factor is confirmed by Nower and Blaszczynski (2010) that found that, for problem gamblers, the most important reason to play machines is to earn incomes and to escape from their problems. The positive aroused feelings that appear in the anticipation of money

\footnotetext{
${ }^{11}$ Among those $45,6 \%$ participants were non-problems gamblers, 41,6\% had minimal gambling problems, 9,3\% were sub- clinical gamblers and $3.5 \%$ probable pathological gamblers after completing the SOGS test (The South Oaks Gambling Screen proposed by Lesieur and Blume, 1987)
}

\section{DE GRUYTER OPEN}


Murgea, A. (2015).

International Confidence in Italian Economy. A Spread and Gambling Analysis

could, because of the activation of the nucleus accumbers, promote risk taking and reinforce the gambling activities (Kuhnen \& Knutson, 2005; Knutson et al., 2005).

Several factors as early gaming history, life circumstances, personality traits, genetic roots and environment, the association with other substance use disorders, gambling itself and the "near miss" situations were proven to represent important determinants in gambling persistence and intensity.

Early gambling history seems to be an important factor that enhances gamblers motivations. A winning history makes individuals to value more the positive consequences than the negatives ones (pay attention more to wins than to losses) and to overestimate their winning chances (Lichtenstein et al, 1982; Weinstein, 1980). The explanation could be rooted in the human cortex functioning. Besides the rational decisions, human cortex seems to be also ruled by hedonic principles as searching pleasure. If a winning situation has occurred, this generated a flow of dopamine, larger as the forecast process was more complex. The memories of the pleasure felt in the winning moment create the premises for persistence in gambling, make the individual overconfident and increase the control illusion (Langer, 1975). As a supplementary factor that increase the control illusion and gambling persistence, pretty often gamblers share the belief that if the deviations from expected behaviours in a random process are observed repeatedly, futures deviations in the opposite direction are more likely to occur at the futures processes (for instance after a series of black at the roulette the expected result is expected to be red even if in fact the probability is equal, independent of the previous results). This error, often called "gambler's fallacy" occurs because the human brain does not function as a neutral and objective computer (Ayton \& Fisher, 2004; Croson \& Sundali, 2005). Confronted with a large quantity of information and decisions human cortex processes the information through simplifications, trend extensions, heuristics and emotional subjective filters able to significantly reduce the period needed for analysis and decision. All these irrational beliefs and cognitive biases contribute to gambling behaviour. As the frequency of gambling increases those patterns could become more automatic and the individual could become more prone to become unable to stop from gambling.

Life circumstances could influence the gambling propensity, but the type of the preferred game seems to be different, depending of the nature of the situation. In stressful situations individuals become dysphoric in their mood and start to search a way to escape reality as playing with electronic gaming machines (Sharpe, 2002). On the other hand, high levels of boredom associated with low levels of arousal could represent an important motivational factor for horse race or /and casino games, as a way to reach an optimum level of arousal (excitement). Using gambling to fulfil different function leads to reinforcing gabling behaviour in the framework of some pre-existing cognitions patterns (gamblers continue to gambler no matter if they win or lose). What begins as a social gambling can result for a

DE GRUYTER OPEN
Timisoara Journal of Economics and Business | ISSN: 2286-0991 | www.tjeb.ro Year 2015 | Volume 8 | Issue 1s | Pages: 70-89 
Murgea, A. (2015).

International Confidence in Italian Economy. A Spread and Gambling Analysis

percentage of the population in a pathological behaviour ${ }^{12}$. This is likely to be mediated by poor coping strategies determined inter alia by personality traits, genetic roots or environment, other external factors as alcohol or drug abuse or gambling itself.

Several studies point out the connection between personality traits and gaming behaviour. Anxiety has been shown to play a significant role in development of addictive behaviours (Jacobs, 1986; Henry, 1996; Ste-marie, et al., 2002; Rodda et al., 2004). In the same line of thinking impulsivity (Vitaro et al.,1999) or aggression and narcissistic personality traits may predispose some individuals to gambling addictions (Kim et al., 2008). On the other side gambling is associated with a large plethora of emotions described by pathological gamblers. The gamblers are betting even if they are aware of the fact that it is not in their best interest. Anxiety or excitement that appears prior to gambling is replaced by the pleasure or the relief from tension in the period of gambling but in the end it could be followed by guilt or remorse (Lesieur, 1977).

Genetic roots or the environment seems to explain, even in if in small proportion, the gambling addiction because gambling is a social behaviour embedded in specific environmental and culture settings. Adults who have a parent or another family member with gambling problems are more prone to develop pathological gambling then the ones with no history in their family or during their childhood experience (Volberg \& Steadman, 1989; Winters \& Rich, 1989; Eisen et al, 1998; Reith \& Dobbie, 2011). A stronger effect seems to be present for the sons with gambling fathers than for the daughters with gambling mothers and for more severe parents' problems then for less severe forms (Walters, 2001).

A very important issue to be addressed is the nature of the places where gambling is available because due to the nature of the venue very often the gambling is associated with alcohol consumption (it is very common for instance for casinos to offer free alcohol to players while they are engaged in gambling). Alcohol consumption severely impacts on selfcontrol and predicts persistence in the gambling (Sharpe \& Tarrier, 1993; Kyngdon \& Dickerson, 1999).The individuals that consume alcohol during gambling are shown to be

\footnotetext{
${ }^{12}$ Going beyond the limit of a normal recreational game, pathological gambling was first defined in the third edition of the Diagnostic and Statistical Manual of Mental Disorders (APA, 1980) and modified in the fourth edition (APA, 1994, p. 615) as "persistent and recurrent maladaptive gambling behaviour that disrupts personal, family or vocational pursuits". Essentially pathological gambling is characterized by next features: (i)chronically unable to resist gambling impulses, (ii) relies on others to provide money for desperate financial situations, (iii) preoccupied with gambling or with ways to obtain money to gamble (iv) needs to increase the amounts or frequency of gambling to obtain desired excitement, (v) feels restless or irritable if not able to gamble, (vi) consistently losing money and going back again to try to win back losses ('chasing') (vii) tries repeatedly to reduce or stop gambling, (viii) sacrifices or jeopardizes important social, occupational or recreational activities to gamble (ix) gambles to escape from problems or to relieve negative moods $(x)$ lies to family members, therapist, or others to conceal the extent of involvement with gambling.
}

\section{DE GRUYTER OPEN}


Murgea, A. (2015).

International Confidence in Italian Economy. A Spread and Gambling Analysis

prone to increased arousal and seems to be twice as likely to stop only when they have run out of money. Most recent studies have shown that pathological gambling is proved to be associated with substance use disorders (for instance in the Petry's study from 2005, over $70 \%$ from the sample of pathological gamblers have been diagnosed with alcohol problems and over $30 \%$ with drug problems).

Gambling itself could contribute to the development of pathological gambling through the self-enhancing mechanism. The gambling consequences as lying to the family, financial problems, job loss, remorse, self-esteem loss are important mood and cognitive disturbing factors. Trying to escape from reality, gamblers irrationally associate a higher importance to the winning they could obtain from gambling compared with the further loss they could experience, creating a vicious circle. Neuronal studies have shown frontal lobe dysfunction relative to controls, decreased concentration, problems with memory and executive functioning in the case of gamblers (Rugle \& Melamed, 1993; Regard et al., 2003) that could motivate this kind of attitude.

An important motivational factor in gambling persistence is the so called 'near miss' (Sharpe, 2002; Côté et al.,2003). If the gamblers' sequences are very close to the winning combination it could convince them that the winning is really close and it could enhance their willingness to continue to play, hoping that the loss will be recuperated. In a way the gambler seems to see the "near misses 'as a prospective win rather than a current loss.

As one can easily notice, at least some of the enunciated factors (money, life circumstances, anxiety) are strongly correlated with the financial crisis. If some of the others as genetic roots, alcohol consumption or "near miss" motivations are individual ones with influences hard to aggregate, financial crisis severely impact on the first three factors for a large sample of population. This represents a solid premise for the correlation we are trying to asses.

\section{Data}

In order to illustrate how the financial crises, mediated by the confidence loss, impact on the Italian gambling industry we decided to use three categories of variables for the period January 2009-October 2012: gambling industry variables, confidence variables and macroeconomic variables. In the first category we use the monthly growth rate of played amounts for eight gambling categories: slot machines, bingo, horse races, sport games, lottery, lotto, supernalotto and skill games ${ }^{13}$. As confidence proxies we chose the monthly

\footnotetext{
${ }^{13}$ All played amounts values are reported by Autonomous State Monopolies Administration of the Ministry of the Economy and Finance (Agenzia delle Dogane e dei Monopoli) on their web site
}

\section{DE GRUYTER OPEN}

Timisoara Journal of Economics and Business | ISSN: 2286-0991 | www.tjeb.ro Year 2015 | Volume 8 | Issue 1s | Pages: 70-89 
Murgea, A. (2015).

International Confidence in Italian Economy. A Spread and Gambling Analysis

growth rate of spread between the 10 years yield of Italian and German government bonds for international confidence ${ }^{14}$ and the monthly growth rate of Economic Sentiment Indicator (ESI) for Italian citizens' confidence ${ }^{15}$. In order to isolate the unemployment effect described by previous papers during the crises especially in lottery case, we have used monthly unemployment growth rates ${ }^{16}$ as a macroeconomic indicator.

A short look at the gambling industry segments shows an important values increase especially in the slot machines case (see Figure 1). Encouraged by government regulatory attitude and by the huge amount of publicity, after the legalisation occurred in 2004 slot machines have overtaken lotteries, horses and football accounting nowadays for more than half of total spending for gambling ${ }^{17}$. In the other categories the evolutions are less significant. One could notice the increase in skill games after the new set of regulations presented in early 2011. The Italian government allowed back then cash games of online poker and casino and introduced a minimum $90 \%$ payback rate of what is collected from players. Spread between Italian and German bonds present an important increase starting from 2010 as a result of a growing uncertainty regarding Italian economy's ability to cope with the crisis. Economic sentiment Index have negative values the entire period and unemployment show a constant consistent increase especially after April 2011.

In term of growth rates, in Appendix are presented the main descriptive statistics for all the variables. To avoid any spurious results we have checked the stationary with Augmented Dickey-Fuller test, Elliott-Rothenberg-Stock DF-GLS test and Phillips-Perron test for all time series and none of them have unit roots.

\section{Lack of Confidence and Gambling Behaviour}

The starting point in our model is the assumption that the gamblers, or at least a specific category, are indeed influenced by the international lack of confidence in Italian post-crisis economy and by internal economic sentiment. Our special interest regards the skill games category because the gamblers who choose this kind of games are more prone to be

\footnotetext{
${ }^{14}$ The spread growth rates are calculated based on the statistical data offered by European Commission

${ }^{15}$ The Economic Sentiment Indicator represent a composite indicator calculated by the European Commission based on five sector confidence indicators, with different weights: Industrial confidence indicator, Services confidence indicator, Consumer confidence indicator, Construction confidence indicator Retail trade confidence indicator. Confidence indicators are arithmetic means of seasonally adjusted balances of answers to a selection of questions defined within the Joint Harmonised EU Programme of Business and Consumer Surveys.

${ }^{16}$ Unemployment monthly growth rates are computed using the data offered European Commission

${ }^{17}$ Especially in Rome and its surrounding towns where the spending on gambling per head reaches the highest value from all Italy, slot machines parlours have grown in number with the same speed as the families stores have shut down.
}

\section{DE GRUYTER OPEN}


Murgea, A. (2015).

International Confidence in Italian Economy. A Spread and Gambling Analysis

influenced by the information regarding the spread or ESI18 (the skill games category requires a certain level of education and computer abilities compared with the other categories, both needed in order to access and understand financial information as spread).

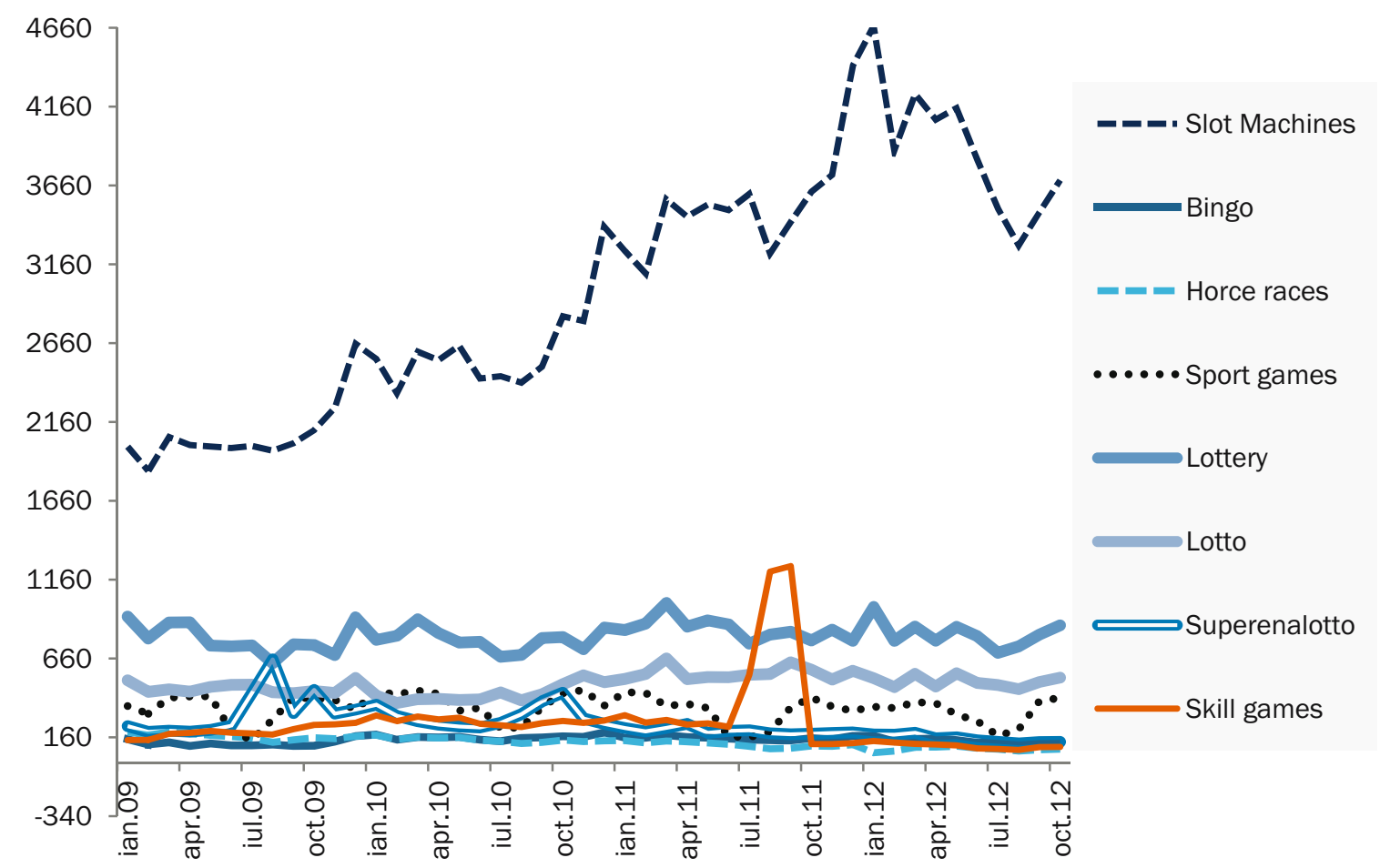

Figure 1. Monthly played amounts in Italian gambling industry

Starting from this alleged assumption, we went further considering that there is a non-linear positive correlation between spread and skill games (in terms of growth rates) that could be explained by an increased propensity for gambling as an ultimate solution in the case of a higher international lack of confidence. The amount played in different games, including skill games has an important autoregressive feature justified both by the "near miss" factor enunciated before and by the limited character of the resources engaged in this activity. In the first place, increased previously played amounts could stimulate the willingness to continue to play even if the gambler lost just because he feels that the winning are really close. In time the "near miss" factor tend to diminish and the lack of resources prevails in decision. The spread influence over a decision like gambling, made under uncertainty, is mediated by personal traits. The decisions each individual takes on daily basis are clearly constricted by personal circumstances, feelings and emotions. Spread evolutions

${ }^{18}$ The correlations were tested for all the categories but except skill games and lottery the results were non significant. The results are not included for space saving in the paper but are available on request.

DE GRUYTER OPEN
Timisoara Journal of Economics and Business | ISSN: 2286-0991 | www.tjeb.ro Year 2015 | Volume 8 | Issue 1s | Pages: 70-89 
Murgea, A. (2015).

International Confidence in Italian Economy. A Spread and Gambling Analysis

represented an important emotional trigger of anxiety among Italian educated population since its increase is highly correlated with the probability of a debt crises in Italy similar with the one occurred in Greece.

To find whether the relationship is significant and robust we test the following benchmark specification:

$$
g r_{-} \text {skill }_{t}=\alpha+\sum_{i=1}^{n} \beta_{i} g r_{-} \text {skill } t_{t-i}+g r_{-} \text {spread }^{\wedge} 2+\varepsilon_{t}
$$

where gr_skill represents the growth rate for the amounts played in skill games, gr_spread the growth rate of spread, $\alpha$ stands for intercept and $\varepsilon$ for standard error.

We have tested the simple version of the model as in the equation above (model 1 ) and three other alternative models including also other variables: a model including the unemployment growth rate (model 2), ESI growth rate (model 3) or both of them (model 4). The results are presented in the Table 1.

Table 1. Relationship between skill games and spread

\begin{tabular}{|c|c|c|c|c|}
\hline Variables & Model 1 & Model 2 & Model 3 & Model 4 \\
\hline$\alpha$ & $\begin{array}{l}-0.075251^{*} \\
(0.043167)\end{array}$ & $\begin{array}{l}-0.083682^{*} \\
(0.043979)\end{array}$ & $\begin{array}{l}-0.070994 \\
(0.043593)\end{array}$ & $\begin{array}{l}-0.079221^{*} \\
(0.044620)\end{array}$ \\
\hline gr_skill(-1) & $\begin{array}{l}0.509716 * * * \\
(0.115413)\end{array}$ & $\begin{array}{l}0.508113 * * * \\
(0.115420)\end{array}$ & $\begin{array}{l}0.531517 * * * \\
(0.118540)\end{array}$ & $\begin{array}{l}0.527571 * * * \\
(0.118890)\end{array}$ \\
\hline gr_skill(-2) & $\begin{array}{l}-0.505939 * * * \\
(0.117279)\end{array}$ & $\begin{array}{l}-0.512349 * * * \\
(0.117464)\end{array}$ & $\begin{array}{l}-0.524682 * * * \\
(0.119672)\end{array}$ & $\begin{array}{l}- \\
0.528719 * * * \\
(0,120028)\end{array}$ \\
\hline gr_spread^2 & $\begin{array}{l}5.349717 * * * \\
(1.065682)\end{array}$ & $\begin{array}{l}5.064702 * * * \\
(1,103017)\end{array}$ & $\begin{array}{l}5.186241 * * * \\
(1.086007)\end{array}$ & $\begin{array}{l}4.942979 * * * \\
(1.120883)\end{array}$ \\
\hline gr_unemployment & & $\begin{array}{l}1.475494 \\
(1.473715)\end{array}$ & & $\begin{array}{l}0.909317 \\
(1.355386)\end{array}$ \\
\hline gr_esi & & & $\begin{array}{l}-0.325222 \\
(0.378052)\end{array}$ & $\begin{array}{l}-0.288315 \\
(0.381084)\end{array}$ \\
\hline Number of observations & 43 & 43 & 43 & 43 \\
\hline Adjusted R² & 0.499051 & 0.499082 & 0.495690 & 0.493381 \\
\hline F-statistic & 14.94698 & 11.46153 & 11.32052 & 9.180522 \\
\hline
\end{tabular}

* significant at $10 \%$ level, ** at $5 \%$ level, *** at $1 \%$ level

As one can see the most robust one, model 1, shows a strong, positive, statistically significant correlation between skill games and spread that validates our initial assumption.

DE GRUYTER

\section{OPEN}

Timisoara Journal of Economics and Business | ISSN: 2286-0991 | www.tjeb.ro

Year 2015 | Volume 8 | Issue 1s | Pages: 70-89 
Murgea, A. (2015).

International Confidence in Italian Economy. A Spread and Gambling Analysis

Also the reverse sign in the coefficients of gr_skill(-1) and gr_skill(-2) could signify a small degree of stability in the market propensity for these games. ESI and unemployment do not seem to be correlated. Confronted with the financial crisis and the international averse position it seems that a segment of the Italian population that represent usually the target group for skill games started to orientate more towards gambling once the level of confidence decreased in the international financial markets. The expansion of time spend on the internet in other various purposes and the huge amount of publicity made on TV and in on-line environment to this kind of games could also represent a catalyst of these evolutions.

The only other category that seems to be correlated with spread, using a similar model, but in the opposite sense is lottery (see the Table 2).

$$
g r_{-} \text {lottery }_{t}=\alpha+\sum_{i-1}^{n} \beta_{i} g r_{-} \text {lottery }_{t-i}+g r_{-} \text {spread }^{\wedge} 2+\varepsilon_{t}
$$

where: gr_lottery stands for lottery played amounts growth rate

Table 2 Relationship between lottery and spread

\begin{tabular}{|c|c|c|c|c|}
\hline Variables & Model 1 & Model 2 & Model 3 & Model 4 \\
\hline$\alpha$ & $\begin{array}{l}0.038103 * * \\
(0.018659)\end{array}$ & $\begin{array}{l}0.036003^{*} \\
(0.019189)\end{array}$ & $\begin{array}{l}0.037354^{\star} \\
(1.957606)\end{array}$ & $\begin{array}{l}0.034948 * \\
(0.019676)\end{array}$ \\
\hline gr_lottery(-1) & $\begin{array}{l}-0.637178 * * * \\
(0.144775)\end{array}$ & $\begin{array}{l}-0.640019 * * * \\
(0.146145)\end{array}$ & $\begin{array}{l}-0.636177 * * * \\
(0.146570)\end{array}$ & $\begin{array}{l}0.638965 * * * \\
(0.17921)\end{array}$ \\
\hline gr_lottery(-2) & $\begin{array}{l}-0.300617 * * * \\
(0.143263)\end{array}$ & $\begin{array}{l}-1.207750 * * \\
(0.144535)\end{array}$ & $\begin{array}{l}-1.106463 * * \\
(0.145087)\end{array}$ & $\begin{array}{l}-1.177770 * * \\
(0.146351)\end{array}$ \\
\hline gr_spread^2 & $\begin{array}{l}-1.134573 * * \\
(0.454945)\end{array}$ & $\begin{array}{l}-1.207750 * * \\
(0.476972)\end{array}$ & $\begin{array}{l}-1.106463 * * \\
(0.471797)\end{array}$ & $\begin{array}{l}-1.177770 * * \\
(0.491055)\end{array}$ \\
\hline gr_unemployment & & $\begin{array}{l}0.364747 \\
(0.648889)\end{array}$ & & $\begin{array}{l}0.387407 \\
(0.658265)\end{array}$ \\
\hline gr_esi & & & $\begin{array}{l}0.044120 \\
(0.161501)\end{array}$ & $\begin{array}{l}0.054316 \\
(0.163824)\end{array}$ \\
\hline Number of observations & 43 & 43 & 43 & 43 \\
\hline Adjusted R² & 0.336927 & 0.325124 & 0.320812 & 0.308938 \\
\hline F-statistic & 8.113827 & 6.058423 & 5.959639 & 4.744199 \\
\hline
\end{tabular}

* significant at $10 \%$ level, ** at $5 \%$ level, *** at $1 \%$ level

This kind of correlation seems to be a little bit unexpected since the lottery is one of the purely fortune games that are considered a simple way to change your life. One would expect an increase of lottery games along with a decrease in ESI or spread but the real data

DE GRUYTER OPEN
Timisoara Journal of Economics and Business | ISSN: 2286-0991 | www.tjeb.ro Year 2015 | Volume 8 | Issue 1s | Pages: 70-89 
Murgea, A. (2015).

International Confidence in Italian Economy. A Spread and Gambling Analysis

show another pattern. The previously played amounts seems to be negatively correlated with the current gambling tendency, a normal behaviour if we are considering it. The one who played the lottery in the last months and did not gain anything will choose not to do it now. Considering the spread, it seems that an increase value of spread generates among the lottery usual clients a reduced propensity to participate in a lottery, as a reaction to the increased uncertainty in the financial future outcomes.

In all the tests, for all the categories ESI and unemployment seems to be uncorrelated with the played amount, despite de initial assumption we have made. Italians seems to be more interested by the international financial markets' reactions then by any other variable taken into account.

The gambling behaviour and its motivations are indeed even more complex than one could think of at a first look. The financial crisis and its effects seem to impact on the gambling behaviour not only because the governments chose to encourage gambling behaviour to alleviate the crises effect (Verona, 2010) but the effect seems also to be mediated by a more subtle channel as the international financial markets lack of confidence in the national economy. But the government's role in enhancing gambling propensity cannot be neglected because it can act as a catalyst for the other effects as the spread effect stated in this paper.

The topic is particularly sensitive because of the economical growth and the well-being implications.

On one side, because gambling is considered as a provider of multiple recreational, social and economic benefits (enhanced economic growth, unemployment reduction, higher wages and payments to capital), some of the scholars support the idea of individual choice and less restrictive regulations of the gambling industry as a result of a collaborative framework among stakeholders, regulators and industry (Blaszczynski et al., 2004; Bandolfi, 2008). In fact there are relatively small numbers of studies that examines casinos and other forms of gambling stimulate the economic growth or supplement the state government revenues. Based on sample of US states annual data that range from 1991 to 2005, Walker and Jackson (2007) found that there is a short-term positive impact of casino gambling on economic growth, but that the effect dies out on longer term. Same conclusion could be found in Walker and Jakson $(2008,2009)$ based on an analysis of the casino industry recovery and development post Katrina hurricane. The positive influence of the casino industry could be explained on the one side as a capital and labor effects and on the other side as a result of the increase of tourism revenues. Fink et al. (2004) analyzed the impact of the lottery revenue increase on the overall tax revenue and concluded that there was a negative correlation between the two variables, accompanied by significant structural changes in the constitution of the tax revenue (once the lottery revenues increase the overall tax and the specific excise taxes decreases) (Kearney, 2005).

On the other hand the gambling industry could "cannibalize" other local industries, generate increased social cost once the individuals develop gambling problems, increase criminality and cause financial and family distress. Supporters of the maximum restrictive state

\section{DE GRUYTER OPEN}


Murgea, A. (2015).

International Confidence in Italian Economy. A Spread and Gambling Analysis

intervention allege that gambling should be framed as a public health issue and treated like a serious threat to well being (Korn et al., 2003; Adams et al., 2009). Analyzing the gambling regulations from 11 state of USA, LaBrie and Shaffer (2003) concluded that the largest part of the regulatory acts are focused on the secondary (for instance credit restrictions or alcohol restriction) or tertiary intervention level (self-exclusion, help line and treatment) and just a few are oriented on the most effective, first intervention level (public awareness programs, advertising restrictions). In UK, Light (2007) states that the last regulatory act could generate a lot of damages for the US's citizens well being because does not frame anymore the gambling as a harmful activity but as mainstream leisure activity. The same state attitude is pointed out in Italy by Batistiani et al. (2011). They see the large growing of the game industry in Italy as a result of a cultural revolution generated by the transfer from the strict containing approach to a hard liberalizing approach.

\section{Conclusions}

Several social, psychological, financial, environmental or genetic motivations for gambling are present in the literature. The financial crises and their effects represent one of the main influence factors since their repercussions can be found in various fields. What is interesting to be noticed is that a purely financial variable as spread seems to be highly correlated with the gambling propensity for skill games. An increased gambling propensity to play skill games was found in the periods where the confidence in the efficiency of Italian economy to cope with the crisis was low. Also the spread growth seems to be negatively correlated with the growth rates of the played amounts in lotteries, opposite to lotteries' studies that show a higher propensity for playing this kind of games in crises periods. ESI and unemployment does not seem to be correlated in any way with the Italian gambling behaviour.

The results can be explained using various approaches. On one side, an important cause for the found connection is represented by encouraging public policies, both in the fiscal area and in marketing. Confronted with huge budgetary deficits the development of gambling sector was seen as a saver choice, as a better alternative compared to the loans from the international financial markets. From this point of view, the connection between spread and gambling seems to be expected. On the other side, the spread increase came as a result of the latest crisis. The crisis itself generated a shift in individual psychology and behaviour. The financial turmoil and the indirect message sent by international markets through the spread increase generated a grown anxiety among Italians that started to see gambling as the only chance to improve their life quality.

The results of this study can definitely contribute to a broader view of the gambling motivations. Very often in gambling studies money or more precise lack of money are seen as an important factor but little attention is paid to the future money perspective. The uncertainty regarding the

DE GRUYTER OPEN
Timisoara Journal of Economics and Business | ISSN: 2286-0991 | www.tjeb.ro Year 2015 | Volume 8 | Issue 1s | Pages: 70-89 
Murgea, A. (2015).

International Confidence in Italian Economy. A Spread and Gambling Analysis

future incomes can be sometimes a very important factor, even stronger than the current amount of incomes. The strong correlation between spread and skill games could represent an example in this sense. This is the reason why the public policies oriented towards reducing public debt using gambling fiscal revenues could be an even more dangerous measure then at the first look. Financial crisis could act as an enhancing factor itself for gambling industry or at least for a segment, both through the income reduction and through uncertainty level raise. If ones add here the governments encouraging regulatory interventions the effects in general population wellbeing could be even more severe for the future.

\section{Acknowledgement:}

This paper is dedicated to the memory of Giancarlo Marini, the one who inspired it and was in this sense its moral co-author. Without his contribution this paper would not exist. Also, I would like to express my gratitude towards Francesco Verona, who was so kind to share with us the vast bibliographic material he had used in his paper and book regarding Italian gambling industry. Finally, I consider this opportunity to acknowledge the help of Pasquale Scaramozzino, Constantin Chilarescu and two other anonymous reviewers.

\section{References}

Abt, V., \& McGurrin, M. C. (1992). Commercial gambling and values in American society: The social construction of risk. Journal of Gambling Studies, 8(4), 413-420.

Adams P, Raeburn, J., \& de Silva K.(2009). A question of balance: prioritizing public health responses to harm from gambling. Addiction, 104(5), 688-91.

American Psychiatric Association. (1980). Diagnostic and Statistical Manual of Mental Disorders, 3rd edn. Washington, DC: American Psychiatric Association.

American Psychiatric Association (1994). Diagnostic and Statistical Manual of Mental Disorders, 4th edn. Washington, DC: American Psychiatric Association.

Ayton, P., \& Fischer, I. (2004). The hot hand fallacy and the gambler's fallacy. Two faces of subjective randomness. Memory \& Cognition,32(8), 1369-1378.

Batistiani, L., Gori, M., Colasante, E., Siciliano, V., Capitanucci, D., Jarre, P., et al. (2011). Complex factors and behaviours in the gambling population of Italy. Journal of Gambling Studies, 29(1), 1-13.

Binde, P. (2005). Gambling Across Cultures: Mapping Worldwide Occurrence and Learning from Ethnographic Comparison. International Gambling Studies, 5(1), 1-27.

Blaszczynski, A., \& Nower, L. (2002). A pathways model of problem and pathological gambling. Addiction, 97, 487-499.

Blaszczynski, A., Ladouceur, R., \& Shaffer, A.(2004). Science-based framework for responsible gambling: The Reno model. Journal of Gambling studies, 20(3), 301371.

Bondolfi G, Jermann F., Ferrero F., Zullino D., \& Osiek C. (2008). Prevalence of Pathological Gambling in Switzerland after the Opening of Casinos and the Introduction of New Prevention Initiatives. Acta Psychiatria Scandinavia, 117 (3), 236-9.

Calvosa, P. (2013). The regulated internet gambling industry in Italy: business models compared. European Scientific Journal, 9(22), 1-20.

DE GRUYTER OPEN
Timisoara Journal of Economics and Business | ISSN: 2286-0991 | www.tjeb.ro Year 2015 | Volume 8 | Issue 1s | Pages: 70-89 
Murgea, A. (2015).

International Confidence in Italian Economy. A Spread and Gambling Analysis

Chantal, Y., Vallerand, R. J., \& Vallières, E. F. (1994). Construction et validation de l'échelle de Motivation Relative aux Jeux de Hasard et d'Argent. Society and Leisure, 17, 189-212.

Coman, G.J., Burrows, G.D.\& Evans, B.J.(1997). Stress and anxiety as factors in the onset of problem gambling: implications for treatment. Stress Medicine, 13, 235-244.

Côté, D., Caron, A., Aubert, J., Descrochers, V., \& Labouceur, R. (2003). Near wins prolong gambling on a video lottery terminal. Journal of Gambling Studies, 19(4), 433-438.

Croson, R. \& Sundali, J. (2005). The gambler's fallacy and the hot hand: empirical data from casinos. Journal of risk and uncertainty, 30(3), 195-209.

Dadayan, L. \& Ward, R. B. (2009). For the first time, a smaller jackpot: Trends in state revenues from gambling. Albany: The Nelson A. Rockefeller Institute of Government.

Downes, D., Davies, B. P., David, M. E., \& Stone, P. (2006). Gambling as a sociological problem. In J. F. Cosgrave (Ed.), The sociology of risk and gambling reader (pp. 101120). New York, London: Routledge.

Eisen S. A., Lin N., Lyons M. J., Scherrer J. F., Griffith K., True W. R. , et.al. (1998). Familial influences on gambling behavior: an analysis of 3359 twin pairs. Addiction 93, 1375-1384.

Ernst\&Young. (2011). Market overview: the 2011 global gaming bulletin.

Fink, S., Marco, A., \& Rork, J. (2004). Lotto nothing? The budgetary impact of state lotteries. Applied Economics, 36, 2357-2367.

Frasca, R. (2008). La dimensione ludica nella società romana antica in Cambi.F and Staccioli,G (ed) I/ gioco in Occidente: Storie, teorie, practihe, (pp.13-25), Roma: Armando.

Gabriel, K. (2003). Playing the gods. Gambling and spirituality: A new anthropological perspective. In G. Reith (Ed.), Gambling: Who wins? Who loses (pp. 334-347). Amherst, NY: Prometheus Books.

Gu, Z. (1999). The Impact of the Asian Financial Crisis on Asian Gaming Activities: An Examination of Las Vegas Strip Casino Drops. Current Issues in Tourism, 2(4), 354365.

Henry, S. L. (1996). Pathological gambling: Etiologic considerations and treatment efficacy of eye movement desensitization/reprocessing. Journal of Gabling Studies, 12(4), 395405.

Horwáth, C. \& Paap, R. (2012). The effect of recessions on gambling expenditures. Journal of Gambling Studies, 28(4),703-717.

Jacobs, D. F. (1986). A general theory of addictions. A new theoretical model. Journal of Gambling Studies, 2(1),15-31.

Kearney, M. (2005). State lotteries and consumer behavior. Journal of Public Economics, 89(11-12), 2269-2299.

Kim, E. J., Namkoong, K., Ku, T., \& Kim, S. J. (2008). The relationship between online game addiction and aggression, self-control and narcissistic personality traits. Journal of the Association of European Psychiatrists, 23(3), 212-218 .

Klingemann, H. K. H. (1995). Games, risk and prevention: The rehabilitation of "Homo Ludens" . Journal of Drug and Alcohol Education, 41, 99-12.

Knutson, B., Taylor, J., Kaufman, M. T., Peterson, R., \& Gover, G. (2005). Distributed neural representation of expected value. Journal of Neuroscience, 25, 4806-4812.

DE GRUYTER OPEN 
Murgea, A. (2015).

International Confidence in Italian Economy. A Spread and Gambling Analysis

Korn, D., Gibbins, R., \& Azmier,J. (2003). Framing public policy towards a public health paradigm for gambling. Journal of Gambling Studies, 19(2), 235-257.

Kuhnen, C. M., \& Knutson, B. (2005). The neural basis of financial risk taking, Neuron, 47, 763-770.

Kumar, A. (2009). Who gambles in the stock market? The Journal of Finance, 64(4), 18891933.

Kyngdon, A., \& Dickerson, M. (1999). An experimental study of the effect of prior alcohol consumption on a simulated gambling activity. Addiction, 94, 697-707.

LaBrie, R., \& Shaffer, H. (2003). Toward a science of gambling regulation: a concept statement. AGA Responsible Gaming Series, 2(2),1-7.

Ladouceur, R., \& Walker, M. (1998). The cognitive approach to understanding and treating pathological gambling. In A. S. Bellack and M. Hersen (Eds.). Comprehensive Clinical Psychology (pp.588-601). New York: Pergamon.

Langer, E. J. (1975). The illusion of control. Journal of Personality and Social Psychology, 32(2), 311-328.

Lee, H.-P., Chae, P. K., Lee, H.-S. \& Kim, Y.-K. (2007). The five-factor gambling motivation model. Psychiatry Research, 150(1), 21-32.

Lesieur, H. (1977). The Chase: career of the compulsive gambler. Oxford, UK: Anchor.

Lichtenstein, S., Fischhoff, B., \& Phillips, L. D. (1982). Calibration of probabilities: The state of the art to 1980 . In D. Kahneman, P. Slovic, A. Tversky. Judgment under uncertainty: Heuristics and biases. (pp. 306-334), Cambridge University Press.

Light, R. (2007). The Gambling Act 2005. Regulatory containment and market control. The modern Law Review, 70(4), 623-653.

Lightsey, O. R., \& Hulsey, C. D. (2002). Impulsivity, coping, stress, and problem gambling among university students. Journal of Counseling Psychology, 49, 202-211.

McCormick, R. A. (1987). Pathological gambling: A parsimonious need state model. Journal of Gambling Behavior, 3, 257-263.

Mikesell, J. L. (1994). State lottery sales and economic activity. National Tax Journal, 47(1), 165-171.

Neighbors, C., Lostutter, T. W., Cronce, J. M. \& Larimer, M. E. (2002). Exploring college student gambling motivation. Journal of Gambling Studies, 18(4), 361-370.

Pavan, E. C. (1993). Quando la cita si diverte: giochi e ideologia urbana: Venezia negli ultimi secoli del Miedievo. In Ortalli, G.(ed), Gioco e giustizia nell'Italia di comune, (pp.156-185), Treviso: Fundazione Bennetton.

Petry, N. M. (2005). Pathological Gambling: Etiology, Comorbidity, and Treatment. Washington, DC: American Psychological Association Press.

Raab, C., \& Schwer, R. K. (2003). The short- and long-term impact of the Asian financial crisis on Las Vegas Strip baccarat revenues. Hospitality Management, 22, 37-45.

Raylu, N., \& Oei, T. P. (2004) Role of culture in gambling and problem gambling. Clinical Psychology Review, 23, 1087-1114.

Reece, W. (2010). Casinos, hotels, and crime. Contemporary Economic Policy, 28, 145-161.

Regard, M., Knoch, D., Gütling E., \& Landis, T. (2003). Brain damage and addictive behavior: a neuropsychological and electroencephalogram investigation with pathologic gamblers. Cognitive \& Behavioral Neurology, 16, 47-53.

Reith, G., \& Dobbie, F. (2011). Beginning gambling: The role of social networks and environment. Journal of Addiction Research and Theory, 19 (6), 483-493.

DE GRUYTER OPEN 
Murgea, A. (2015).

International Confidence in Italian Economy. A Spread and Gambling Analysis

Richard, B. (2010). Diffusion of an economic development policy innovation: Explaining the international spread of casino gambling. Journal of Gambling Studies, 26(2), 287300.

Rodda, S., Brown, S. L., \& Philips, J. G. (2004). The relationship between anxiety, smoking and gambling in electronic gaming machine players. Journal of Gambling Studies, 10(1), 71-81.

Rugle, L., \& Melamed L. (1993). Neuropsychological assessment of attention problems in pathological gamblers. Journal of Nervous and Mental Disease, 181, 107-12.

Sharpe, L., (2002). A reformulated cognitive-behavioural model of problem gambling a biopsychosocial perspective. Clinical Psychology Review, 22, 1-25.

Sharpe, L., \& Tarrier, N. (1992). A cognitive behavioral treatment approach for problem gambling. Journal of Cognitive Psychotherapy: An International Quarterly, 6, 193203.

Ste-marie, C., Gupta, R., \& Derevensky, J. L. (2002). Anxiety and social stress related to adolescent gambling behaviour. International Gambling Studies, 2(1),123-141.

Verona, F. (2010). An overview of Italian Gaming. The state of industry. UNLV Gaming Research \& Review Journal, 14(1), 55-70.

Vitaro, F., Arseneault, L., \& Tremblay, E. (1999). Impulsivity predicts problem gambling in low SES adolescent males. Addiction, 94(4),565-575.

Volberg, R. A., \& Steadman H. J. (1989) Prevalence estimates of pathological gambling in New Jersey and Maryland. The American Journal of Psychiatry, 166, 1618-1619.

Walker, D., \& Jackson, J. (2007). Do casinos cause economic growth? American Journal of Economics and Sociology, 66, 593-607.

Walker, D, \& Jackson, J. (2008). Market-based "disaster relief": Katrina and the casino industry. International Journal of Social Economics, 35, 521-530.

Walker, D., \& Jackson, J. (2009). Katrina and the Gulf States casino industry. Journal of Business Valuation and Economic Loss Analysis, 4(2), article 9.

Walters, G. D. (2001). Behavior Genetic Research on Gambling and Problem Gambling: A Preliminary Meta-Analysis of Available Data, Journal of Gambling Studies, 17(4), 255-271.

Weatherly, J. N., Montes, K. S., \& Christopher, D. M. (2010). Investigating the relationship between escape and gambling. Analysis of Gambling Behaviour, 4, 79-87.

Weinstein, N. D. (1980). Unrealistic optimism about future life events. Journal of Personality and Social Psychology, 39(5), 806-820.

Winters, K. C., \& Rich T. (1998). A twin study of adult gambling behaviour. Journal of Gambling Studies, 14(3), 213-225.

DE GRUYTER OPEN 
Murgea, A. (2015).

International Confidence in Italian Economy. A Spread and Gambling Analysis

\section{Apendix}

\section{Descriptive statistics}

\begin{tabular}{|c|c|c|c|c|c|c|c|c|c|c|}
\hline & $\begin{array}{l}\text { 它 } \\
\text { के } \\
\frac{1}{\text { के }}\end{array}$ & 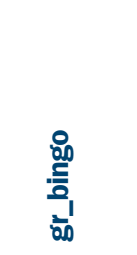 & 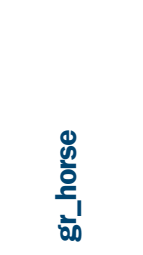 & $\begin{array}{l}\text { tั } \\
\text { के } \\
\text { के }\end{array}$ & 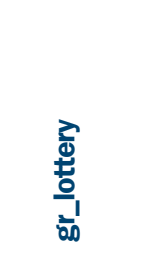 & $\frac{\text { 온 }}{\text { to }}$ & 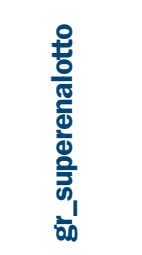 & $\begin{array}{l}\overline{\bar{B}} \\
\text { के } \\
\text { के } \\
\text { के }\end{array}$ & $\begin{array}{l}\text { वृ } \\
\text { ळे } \\
\text { के } \\
\text { के } \\
\text { के }\end{array}$ & 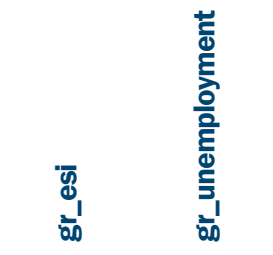 \\
\hline Mean & 0,016802 & 0,003051 & $-0,00932$ & 0,047091 & 0,006179 & 0,005971 & 0,010691 & 0,050299 & 0,027773 & 0,003139 0,011052 \\
\hline Median & 0,007021 & 0 & $-0,03125$ & $-0,013453$ & 0,006329 & 0,008993 & 0,014925 & 0,010204 & 0,024242 & 0,002841 0,010045 \\
\hline Maximum & 0,213571 & 0,265152 & 0,347222 & 0,922535 & 0,352423 & 0,21542 & 0,892704 & 1,460177 & 0,409326 & 0,223485 0,053339 \\
\hline Minimum & $-0,169165$ & $-0,22449$ & $-0,460177$ & $-0,530952$ & $-0,218845$ & $-0,208955$ & $-0,519142$ & $-0,9061$ & $-0,216102$ & $-0,256338-0,036916$ \\
\hline Std. Dev. & 0,08113 & 0,111638 & 0,127348 & 0,316325 & 0,126109 & 0,10339 & 0,225727 & 0,325268 & 0,145177 & 0,099418 0,025575 \\
\hline Skewness & 0,388663 & 0,094246 & $-0,425744$ & 0,934862 & 0,492302 & $-0,031127$ & 1,254023 & 2,22552 & 0,64877 & $-0,047824-0,079257$ \\
\hline Kurtosis & 3,067633 & 2,939026 & 5,666693 & 4,12846 & 2,926214 & 2,365551 & 7,396158 & 13,32873 & 3,033188 & $2,841381,877081$ \\
\hline Jarque-Bera & 1,141518 & 0,073588 & 14,69303 & 8,942412 & 1,82792 & 0,762002 & 48,03094 & 237,1771 & 3,158836 & $0,0643292,411388$ \\
\hline Probability & 0,565096 & 0,963875 & 0,000645 & 0,011434 & 0,400933 & 0,683177 & 0 & 0 & 0,206095 & $0,9683470,299484$ \\
\hline Sum & 0,75607 & 0,13731 & $-0,4194$ & 2,119115 & 0,278055 & 0,268713 & 0,48111 & 2,263455 & 1,24977 & 0,141261 0,497359 \\
\hline Sum Sq. Dev. & 0,289611 & 0,548376 & 0,713568 & 4,402714 & 0,699751 & 0,470339 & 2,241909 & 4,655182 & 0,927362 & 0,434896 0,028779 \\
\hline Observations & 45 & 45 & 45 & 45 & 45 & 45 & 45 & 45 & 45 & 45 \\
\hline
\end{tabular}

DE GRUYTER OPEN
Timisoara Journal of Economics and Business | ISSN: 2286-0991 | www.tjeb.ro Year 2015 | Volume 8 | Issue 1s | Pages: 70-89 